\title{
Tissue-nonspecific Alkaline Phosphatase Blockade Ameliorates Behavioural Deficits and Life- expectancy on Tauopathies
}

\section{Álvaro Sebastián-Serrano}

Universidad Complutense de Madrid Facultad de Veterinaria

Jesús Merchán-Rubira

Consejo Superior de Investigaciones Cientificas

\section{Caterina Di-Lauro}

Universidad Complutense de Madrid Facultad de Veterinaria

\section{Carolina Bianchi}

Universidad Complutense de Madrid Facultad de Veterinaria

\section{Sonoko Narisawa}

Stanford burnham Prebys medical discovery institute

Jose Luis Millan

Stanford Burnham Prebys Medical Discovery Institute

\section{Jesus Avila}

Consejo Superior de Investigaciones Cientificas

\section{Felix Hernandez}

Universidad Autonoma de Madrid

Miguel Diaz-hernandez ( $\nabla$ migueldiaz@ucm.es )

Universidad Complutense de Madrid Facultad de Veterinaria https://orcid.org/0000-0002-1952-4600

\section{Research article}

Keywords: PS19, Alzheimer's disease (AD), Pick's disease (PiD), Levamisole, Muscarinic receptor M1, TNAP, Tissue-nonspecific alkaline phosphatase

Posted Date: June 12th, 2020

DOI: https://doi.org/10.21203/rs.3.rs-33899/v1

License: (1) (1) This work is licensed under a Creative Commons Attribution 4.0 International License.

Read Full License 


\section{Abstract}

The authors have removed this preprint from Research Square. 